\title{
A construção de narrativas de professores sobre o analfabetismo funcional
}

\author{
Alessandra Brito de Paiva \\ PUC- Rio
}

\begin{abstract}
Resumo
O presente artigo de pesquisa tem como objeto a análise dos dados gerados em entrevista realizada com professoras de uma escola municipal da Zona Sul do Rio de Janeiro sobre o tema do analfabetismo funcional. Considerase a entrevista como um meio de suscitação de estórias e de organização das experiências. A análise das narrativas visa observar a construção dos discursos das entrevistadas; verificar a forma que organizam suas experiências e constroem seus posicionamentos, e compreender, por meio do discurso produzido, a percepção dos profissionais da educação do ensino fundamental II sobre o tema.
\end{abstract}

Palavras-chave: estórias, professoras, narrativas, analfabetismo funcional.

\begin{abstract}
This research paper analyzes data based on an interview with public school teachers located in the South Zone of Rio de Janeiro, concerning functional illiteracy. The interviews were considered a way of telling stories and organizing the experiences. The analysis of the narratives aims to observe the construction of the interviewees' speech; check the way their experiences are organized and their positions are built, and to understand, through their discourse, the perceptions of the elementary school professionals on this issue.
\end{abstract}

Keywords: stories, teachers, narratives, functional illiteracy.

\section{INTRODUÇÃO}

O presente trabalho tratou do tema do analfabetismo funcional na perspectiva de professoras do Ensino Fundamental II, tendo como objeto de análise a entrevista realizada com duas docentes, uma de ciências e a outra de português, de uma escola municipal da Zona Sul do Rio de Janeiro. A análise, realizada a partir do conceito e elementos da narrativa apresentados por Labov, visou 1) observar a construção dos discursos das entrevistadas; 2) verificar a forma que organizam suas experiências e constroem seus posicionamentos sobre o analfabetismo funcional; 3) compreender, 
através do discurso, a percepção das profissionais da educação do ensino fundamental II sobre o tema; 4) perceber como ocorre a interação entre as participantes.

A utilização do tema central levou em consideração a permanência, na contemporaneidade, do analfabetismo funcional no plano escolar e os hiatos existentes entre as suas diversas formulações e reformulações conceituais. No presente trabalho, foi utilizada a definição de analfabetismo funcional como uma dificuldade na leitura, na escrita e na prática de cálculos básicos em atividades da vida diária. Tal definição não levou em consideração a escolaridade do indivíduo. Para a realização da pesquisa, considerou-se importante e relevante compreender como as profissionais relataram seus posicionamentos frente à questão, sendo as narrativas levantadas na entrevista um potente meio de organização das experiências e meio de compreender a realidade.

\section{ANALFABETISMO FUNCIONAL}

Para se entender e compreender a realidade escolar do analfabetismo funcional, é necessário conhecer a definição restrita do conceito e a definição adotada pela pesquisa. A definição de alfabetismo foi variando ao longo do tempo. Segundo Montenegro (1958), a UNESCO caracterizava como alfabetizada pessoas capazes de escrever um enunciado simples, relacionado à sua vida diária. Em 1978, a UNESCO sugeriu a adoção dos conceitos de analfabetismo e alfabetismo funcional, sendo considerada alfabetizada funcionalmente a pessoa capaz de utilizar a leitura e a escrita diante das demandas do seu contexto social e apta a usar essas habilidades para continuar aprendendo e se desenvolvendo ao longo da vida.

$\mathrm{Na}$ década de 90, seguindo recomendações da UNESCO, o IBGE passou a divulgar os índices de analfabetismo funcional, tomando como base o número de séries concluídas. Pelo critério adotado então, são analfabetas funcionais as pessoas com menos de quatro anos de escolaridade.

Atualmente, vem se considerando a matemática como parte de um indicador de analfabetismo funcional. Como dito, o conceito de alfabetismo vem sendo concebido de maneira mais ampla a fim de contemplar a diversificação e crescente sofisticação das demandas de leitura e escrita nas situações cotidianas. A compreensão de texto, a comunicação e o entendimento não percorrem a compreensão apenas da língua, mas, também, do entendimento das práticas de leitura e escrita, na quais o papel social da matemática é reconhecido e explicitado. 
A partir disso, o Instituto Paulo Montenegro ${ }^{1}$ apresenta os seguintes níveis de alfabetização:

Analfabeto: condição daqueles que não conseguem executar tarefas simples envolvendo a leitura de palavras ou frases, ainda que uma parcela consiga ler números familiares;

Rudimentar: apresentam a capacidade de localizar informações explicitas em textos curtos e familiares, leem e escrevem números usuais e realizam operações simples envolvendo números;

Básico: são considerados funcionalmente alfabetizados, pois leem e compreendem texto de média extensão, e conseguem executar operações simples. Entretanto, apresentam limitações em operações de maior complexidade;

Pleno: as habilidades não apresentam mais restrições, conseguem compreender e ler texto em situações usuais. Leem textos longos e conseguem inferir as informações. Quando à matemática, resolvem problemas de maior planejamento, além de interpretar gráficos, tabelas e mapas.

Partindo-se do conceito da UNESCO e dos níveis de alfabetismo, utilizou-se a definição de analfabetismo funcional como uma dificuldade do indivíduo na utilização da leitura, da escrita e da prática de cálculos básicos em atividades da vida diária que requerem tais habilidades. Essa definição não levou em consideração a escolaridade do indivíduo, apenas a sua capacidade de usar tais aptidões frente às demandas diárias.

\section{A ENTREVISTA E A NARRATIVA}

Como objeto de trabalho, foi utilizada a entrevista realizada com duas professoras de Ensino Fundamental II de uma escola pública da Zona Sul do Rio de Janeiro. A partir do discurso, foram analisadas as narrativas construídas, considerandose as estórias narradas como forma de compreensão da vida em sociedade, como afirma Bastos (2005). Por meio da entrevista, as entrevistadas puderam apresentar e organizar, mentalmente e cronologicamente, suas experiências sobre o analfabetismo funcional, tornando, assim, as narrativas um potente objeto de percepção da realidade.

A entrevista é um meio de suscitação de narrativas pelo qual os falantes constroem seus posicionamentos, organizam suas experiências e assumem seus

\footnotetext{
${ }^{1}$ O Instituto Paulo Montenegro é uma instituição sem fins lucrativos, vinculada ao IBOPE, que tem como objetivo desenvolver e executar projetos na área de educação. Um dos seus projetos é o Inaf- Indicador de Alfabetismo Funcional- que mede os níveis de alfabetismo funcional da população brasileira.
} 
personagens através da co-construção de significados entre o entrevistado e entrevistador (BASTOS; SANTOS, 2013). Ambos os participantes da entrevista são ativos no processo de construção das narrativas e o interlocutor não tem a pretensão de se mostrar neutro, e sim, ser ouvinte e colaborador na construção da narrativa. $O$ entrevistador deve construir um ambiente para o entrevistado falar suas experiências e expressar seus pontos de vista sobre o contexto social.

Através das entrevistas, as profissionais puderam tornar públicas suas opiniões e experiências, podendo fornecer subsídios para a compreensão de percepções dos seus pontos de vista em relação ao analfabetismo funcional. Assim, foram analisadas as narrativas, sua construção, a interação das participantes, a formulação de suas personagens e a forma de organização das experiências.

Para análise das narrativas, foram levadas em consideração os componentes e a estrutura propostos por Labov (cf. Bastos, 2005). Para o autor, é considerado fundamental as estórias terem sequência temporal, ponto e serem contáveis. Ou seja, deve haver uma sequência cronológica; uma razão para a narração; e ser sobre algo relevante, extraordinário, algo não corriqueiro. Como elementos da estrutura da narrativa, ele destaca o resumo, orientação, ação complicadora, resolução, avaliação e coda. Estes elementos não precisam aparecer necessariamente em todas as narrativas, e nem na ordem apresentada.

Comumente, nas narrativas, embora não seja obrigatório, o narrador faz um resumo do que virá a ser dito antes da narração propriamente dita, ou seja, uma breve introdução do que se seguirá. Após a sumarização, pode ocorrer a orientação que irá contextualizar o acontecimento dando informações mais detalhadas, construída com o tempo verbal no imperfeito ou no presente. A seguir, vem a sequência temporal da estória, único elemento obrigatório da narrativa, sendo denominada por Labov de ação complicadora. O evento é narrado dentro de uma ordem lógica e cronológica dos acontecimentos ordenados no passado. Segundo o autor (cf. Bastos, 2005), para haver uma narrativa é preciso uma sequência temporal. Sendo assim, as narrativas que contiverem o mínimo necessário para serem consideradas uma narrativa laboviana são chamadas de narrativas mínimas.

Após a narração dos eventos, os narradores podem utilizar alguns recursos de finalização, sendo um deles a resolução, ou seja, o encerramento da estória pode vir acompanhado de um fechamento. E por fim, o narrador pode sinalizar o fim da narrativa com a coda fazendo com que o ouvinte se sinta convidado para colaborar com algo 
relevante ao que foi narrado, ou o narrador pode utilizá-la para fazer uma avaliação moral do que foi dito.

Outro elemento importante presente nas narrativas é a avaliação; entretanto, diferentemente dos demais, ela não se constitui necessariamente em um espaço próprio na narrativa podendo aparecer de forma encaixada ao longo do texto através de entonação, intensificadores lexicais, repetições e outras alterações na fala. Ela pode ainda ser externa, quando o narrador interrompe sua fala para avaliar diretamente a narrativa, ou quando explica as causas de suas emoções.

\section{ANÁLISE DOS DADOS}

A entrevista da pesquisa, gravada em áudio, foi realizada em uma escola pública da Zona Sul do Rio de Janeiro. A entrevista foi programada previamente, pessoalmente e individualmente com as professoras, que foram informadas sobre o tema, o objeto e o objetivo de compreender e conhecer a experiências de docentes com casos de analfabetismo funcional em sala de aula. No dia marcado, a entrevistadora, ao chegar ao colégio, informou as duas professoras sobre a realização das entrevistas individuais, entretanto, a pedidos das mesmas, a entrevista foi realizada coletivamente. Assim, participaram da entrevista a entrevistadora, Alessandra, e as duas professoras da escola, Solange e Helena, sendo a primeira professora de ciências e a segunda, de português. Apesar das suas formações acadêmicas distintas, ambas as professoras tiveram experiências com alfabetização e já atuaram em outras áreas, tais como EJA2 e projetos de ensino ${ }^{3}$ do governo, respectivamente.

As entrevistadas contaram estórias na entrevista como forma de confirmar e exemplificar seus pontos de vistas, organizando, assim, as suas experiências. Elas também narraram acontecimentos extraordinários de suas vivências em sala, sendo considerados, assim, potentes meios de compreensão da realidade. A análise dessas narrativas foi feita em diálogo com os aspectos teóricos apresentados.

A entrevista teve início sem roteiro prévio e ocorreu na sala de reunião de professores onde, no momento, só havia as participantes. A entrevistadora e as professoras sentaram-se à ponta da mesa formando um triângulo. Alessandra explicou, novamente, o objetivo da entrevista e apresentou a definição de analfabetismo funcional

\footnotetext{
${ }^{2}$ Educação de Jovens e Adultos.

${ }^{3}$ Refere-se aos projetos do Governo que têm como metodologia de ensino, em escolas públicas municipais do Rio de Janeiro, a presença de apenas um professor para lecionar todas as disciplinas do ensino fundamental II, independente da sua formação acadêmica.
} 
utilizada no trabalho. A professora Helena pediu o turno da fala e iniciou seu discurso trazendo três narrativas, duas sobre alunas que possuíam dificuldades, e como cada uma lidou com isso ao longo do período escolar, e uma sobre o seu método de trabalho. Ao final, ela fez uma comparação das duas personagens das narrativas. Ela afirmou que uma das alunas tinha grande fluência na leitura ("fluência absurda" - linha 2), mas não compreendia nada e não conseguiu alterar esse quadro. Entretanto, a outra aluna com uma dificuldade aparentemente maior, pois Helena fala que ela não tinha conhecimento nenhum ("não sabia nada..." - linha 13), conseguiu superar o seu quadro.

A docente trouxe frequentemente na sua narrativa construções para demonstrar a sua preocupação e interesse nas alunas e no tema. Ela repetiu três vezes que a menina tinha uma "fluência absurda" (cf. linhas 2, 6, 20), o que reforçou a sua perplexidade diante da situação, caracterizando, assim, uma avaliação. A professora também relatou que possui embasamento teórico sobre o assunto tratado ("ler sobre leitura/ estudar sobre leitura" linhas 4-5) e reafirmou este arcabouço fazendo uma avaliação quantitativa do que foi estudado ("eu estudei/ li bastante" - linha 20). Entretanto, ela não definiu o que foi pesquisado e aprendido. Helena mostrou a sua frustação por obter avanço apenas com uma parcela de alunos. É possível perceber que, ao trazer uma história de fracasso e uma de sucesso, ela está construindo seu posicionamento como profissional e percebendo e analisando a sua prática como docente.

$\mathrm{Na}$ narrativa da Helena, percebe-se que o que foi avaliado como analfabetismo está relacionado à compreensão textual, mas também associado à fluência da leitura em voz alta. O trabalho de interpretação utilizado pela docente, baseado no grau de compreensão textual que os alunos apresentam, ressalta uma acerta afinidade, ainda que inconscientemente, da profissional com os níveis de alfabetismo. Na estória, ela apresentou que os alunos teriam níveis de leitura e entendimento textuais, e estes seriam avançados de forma gradual.

Como é possível verificar no fragmento abaixo, as narrativas contadas por Helena são extremamente complexas e não seguem, precisamente, a ordem de Labov, não podendo ser consideradas narrativas clássicas. Trata-se de narrativas encaixadas, em que a docente vai juntando estórias, formando uma narrativa maior composta por outras menores que elaboram e reforçam o ponto de vista da entrevistada.

Ela faz uso, inicialmente, do tempo imperfeito dando a ideia de estar relatando um evento extraordinário, mas que, apesar de ser específico, apresenta repetição. As ações complicadoras apresentaram uma cronologia de acontecimentos ordenados de 
modo racional com um fato após o outro. Em muitas se verificou uma relação de consequência ("eu fui começar a ler sobre leitura/ estudar sobre leitura, por que... me chamou a atenção o fato dela não consegui::r interpretar na::da.”- linhas 4-6).

\begin{tabular}{|c|c|c|}
\hline $\begin{array}{l}1 \\
2 \\
3 \\
4 \\
5 \\
6\end{array}$ & Helena & $\begin{array}{l}\text { Eu ti::nha uma aluna que me chamou mu::ito a atenção... porque ela } \\
\text { lia com fluência absurda, só que depois eu chegava para ela e } \\
\text { perguntava “o que você leu?"... Ela não sabia na::da } \downarrow \text {... E é uma coisa } \\
\text { que me dava uma agú::stia/ me angustiou muito que eu fui começar a } \\
\text { ler sobre leitura/ estudar sobre leitura, por que... me chamou a atenção } \\
\text { o fato dela não consegui::r interpretar na::da. Ela lia com uma } \\
\text { fluência absurda= }\end{array}$ \\
\hline 7 & Alessandra & Aham \\
\hline $\begin{array}{l}8 \\
9\end{array}$ & Helena & $\begin{array}{l}\text { = Ma::s na hora de interpretar- E eu trabalhava mu::ito assim... eu } \\
\text { dava e falava assim "leia o que vocês conseguirem"= }\end{array}$ \\
\hline 10 & Alessandra & Aham \\
\hline $\begin{array}{l}11 \\
12 \\
13 \\
14\end{array}$ & Helena & $\begin{array}{l}\text { =Então fazia a interpretação “o que vocês conseguem ler?". Então, era } \\
\text { muito em ci::ma disso. Ela não conseguia nada } \downarrow \text { E eu tinha uma outra } \\
\text { aluna que chegou do nordeste é:: ... não sabia nada... e aí quando eu } \\
\text { falei pra ela que- ela “PROFESSORA, [EU NÃO SEI NADA] }=\end{array}$ \\
\hline 15 & Alessandra & {$[\mathrm{hh}]$} \\
\hline $\begin{array}{l}16 \\
17 \\
18 \\
19 \\
20 \\
21 \\
22\end{array}$ & Helena & $\begin{array}{l}=[E U \text { NÃO SEI LER] COMO QUE VOCÊ VAI ME DÁ UMA } \\
\text { PROVA DESSA?". E no entanto, ela ia aos pouquinhos e ela foi } \\
\text { conseguindo ler. Quer dizer, ela ti::nha uma dificuldade ENORme } \\
\text { mas conseguia/ foi aprendendo a ler e compreender mesmo com a } \\
\text { dificuldade. A outra com uma fluência absurda- e isso, eu estudei...li } \\
\text { bastante, mas até hoje, eu não sei qual o problema dela } \downarrow \text {... } \\
\text { Provavelmente alguma coisa na parte neurológica }=\end{array}$ \\
\hline $\begin{array}{l}23 \\
24\end{array}$ & Alessandra & $\begin{array}{l}=\text { É:: ... porque tem... o problema do analfabetismo funcional é que } \\
\text { ele... se entrelaça com [outras] }\end{array}$ \\
\hline 25 & Helena & [com outras] exatamente $=$ \\
\hline 26 & Alessandra & $=$ Déficits $=$ \\
\hline 27 & Helena & Exatamente $\downarrow$ \\
\hline 28 & Alessandra & $=$ Então, você fazer essa distinção é muito difícil= \\
\hline 29 & Helena & $=$ É muito difícil $\downarrow$ \\
\hline 30 & Alessandra & ... Porque as vezes, você acha que é uma coisa, [mas na realidade] $=$ \\
\hline 31 & Helena & $=[$ não é $]$ \\
\hline 32 & Alessandra & $\ldots$ pode ser outra $=$ \\
\hline $\begin{array}{l}33 \\
34 \\
35 \\
36\end{array}$ & Helena & $\begin{array}{l}\text { = pode ser outra, né:: ... E assi::m... não consegui. É uma frustação. } \\
\text { Porque na época, a gente conseguiu avanço com alguns alunos que } \\
\text { teoricamente liam com mais fluência e não avançava, era uma coi::sa } \\
\text { que não avançava }\end{array}$ \\
\hline
\end{tabular}

Helena iniciou sua primeira estória com um breve resumo e avaliação da narrativa que se sucedeu ("Eu ti::nha uma aluna que me chamou mu::ito a atenção..."- linha 1). A partir de então, ela começou a narrar a estória da aluna que não conseguia interpretar os textos, mas que, apesar disso, possuía fluência na leitura. 
$\mathrm{Na}$ segunda narrativa, ela se posicionou como uma profissional da educação preocupada com o desenvolvimento dos alunos e se mostrou disposta a procurar aprimorar os seus conhecimentos para poder ajudá-los (“E é uma coisa que me dava uma agu::stia/ me angustiou muito que eu fui começar a ler sobre leitura/ estudar sobre leitura,"- linhas 3-5). Ela narrou a dificuldade de uma aluna em interpretar texto e acrescentou que, mesmo com a dificuldade, ao longo do tempo a discente conseguiu superá-la. Para reforçar o seu interesse pelo aprendizado da aluna, a professora narrou a metodologia utilizada para auxiliar os alunos na compreensão textual (“- E eu trabalhava mu::ito assim... eu dava e falava assim “ leia o que vocês conseguirem”. Então fazia a interpretação "o que vocês conseguem ler?”. Então, era muito em ci::ma disso."- linhas 8-9 e 11-12). No meio da fala, a entrevistadora posicionou-se atenta à estória fazendo uso de continuadores (“Aham"-linhas 7 e 10) para confirmar a continuação do turno. E esta estória, do método de ensino utilizado, serviu para exemplificar e orientar em que contexto a aluna apresentava dificuldade, ou seja, quando solicitada uma interpretação textual, ("Então, era muito em ci::ma disso. Ela nãao conseguia nada exatamente a aluna da narrativa não conseguia.

Helena fez uso de repetições, ênfases, alongamentos e pausas para enfatizar a sua história e sua perplexidade diante da dificuldade das alunas. Para ela, aparentemente, uma aluna que lê fluentemente bem pressupõe compreensão de um texto; entretanto, isto não acontecia, segundo a sua narrativa.

A terceira narrativa, de outra aluna com dificuldade, foi utilizada como comparativa à primeira. A estória salientou a incompreensão da Helena de como a discente que tinha a fluência adequada não havia conseguido avanço e a outra que não tinha qualquer conhecimento tinha conseguido superar a colega.

Helena iniciou a narração com um breve resumo do que seria narrado posteriormente ( "E eu tinha uma outra aluna que chegou do nordeste é:: ... não sabia nada"- linhas 12-13), e ao trazer a fala reportada da aluna, Helena dramatizou a narrativa e mostrou a tamanha indignação da aluna ao ser exigido que ela fizesse uma prova (Cf. linhas14 e 16). Como ouvinte, a entrevistadora esboçou uma risada para demonstrar atenção ao que estava sendo dito e envolvimento com a dramatização ("[hh]" - linha 15).

Ao final da narração, Helena fez uma coda avaliativa das estórias apresentadas, retomando-as e fazendo comparação entre as duas narrativas ("Quer dizer, ela ti::nha uma dificuldade ENORme mas conseguia/ foi aprendendo a ler e compreender mesmo com a dificuldade. A outra com uma fluência absurda- e isso, eu estudei/ li bastante, mas até hoje, eu não sei qual o problema 
dela $\downarrow$..." linhas 18-21). Neste fechamento, ela reforçou, novamente, a sua incompreensão do que ocorria com a aluna, entretanto apresentou uma hipótese de que se trataria de algo neurológico ("Provavelmente alguma coisa na parte neurológica="- linhas 2122). A partir desta fala, começou a haver interação e co-construção de significados, ocorrendo uma coda avaliativa co-construída. Alessandra tomou o turno da Helena e completou o pensamento da narradora (“=É:: ... porque tem... o problema do analfabetismo funcional é que ele... se entrelaça com [outras]"- linhas 23-24), e esta por sua vez sobrepôs a sua fala com a da entrevistadora, mostrando conformidade com o que foi dito ("[com outras] exatamente="- linha 25). As participantes, então, mantiveram um discurso coconstruído, fazendo uso de parafraseamento e fala colada. Houve na interação o conhecimento sobre o analfabetismo funcional, como também informações sobre a dificuldade de discerni-lo dos déficits cognitivos.

Para finalizar o seu turno de fala, Helena retomou as narrativas e reforçou, através da coda avaliativa, a sua frustação de não ter conseguido ajudar todos os alunos como gostaria (“E assi::m... não consegui. É uma frustação." - linha 33) e a sua preocupação de aquela situação ter se permanecido estável, durante aquele período letivo ("era uma coi::sa que não avançava.. "'- linhas 35-36).

Após a discussão sobre como a questão da leitura é vista e usada em outras matérias e de como os professores lidam com as defasagens do aluno, Helena trouxe uma narrativa para exemplificar o seu método de ensino para auxiliar os alunos na compreensão textual. Neste momento, Solange e Helena participaram interativamente da entrevista buscando mostrar a distinção na abordagem da leitura nas diferentes disciplinas. Para exemplificar, Helena iniciou uma narrativa mostrando sua experiência nesta habilidade, apresentando atividades já elaboradas, e se posicionou como uma profissional interessada em atender e auxiliar os alunos nas habilidades que lhes são e serão exigidas. Em seu turno, Solange mostrou sua experiência em outras matérias e apresentou uma narrativa sobre o método utilizado para o analfabetismo.

Apesar de as entrevistadas abordarem os seus métodos de ensino, elas não deixaram claro, não apresentaram, o conteúdo do material produzido para os alunos. Em suas narrativas, só fica evidente a noção de gradação existente em relação à capacidade de leitura, ou seja, ir do nível básico ao nível mais avançado. Assim, novamente, a noção dos níveis de alfabetismo é apresentada na narrativa, revelando o conhecimento das profissionais sobre os diferentes graus de compreensão e reforçando que, em suas opiniões, o trabalho mais adequado para melhorar a competência leitora seria trabalhar a 
partir do estágio de compreensão do aluno até a habilidade plena de leitura, como é possível identificar no fragmento a seguir:

\begin{tabular}{|c|c|c|}
\hline $\begin{array}{l}37 \\
38 \\
\end{array}$ & Helena & $\begin{array}{l}\text { Eu tinha folhinhas. O conteúdo eu trabalhava em nível- começava do } \\
\text { nível básico e ia... até o objetivo máximo que eu queria alcançar. }\end{array}$ \\
\hline 39 & Alessandra & Aham \\
\hline $\begin{array}{l}40 \\
41 \\
42 \\
43 \\
44 \\
45 \\
46 \\
47\end{array}$ & Helena & $\begin{array}{l}\text { Então, eu ia trabalhando com folhi::nhas. Dava a primei::ra folha, o } \\
\text { básico. Aí, eles conseguiam fazer. E alguns não conseguiam. E eu } \\
\text { tinha uma folha pronta e dava para o outro que já estava na frente e } \\
\text { eu ficava. Então, as vezes, eu fazia folhas a mais porque ele não saía } \\
\text { daquele objetivo. Você entendeu? Então, a minha/ o meu } \\
\text { planejamento, eu planejava por bimestre/ meu mês, >sei lá< ... e era } \\
\text { o quê.... ficar produzindo folhas que desse conta:: daquela/ daquele } \\
\text { está::gio que eles esta::vam. }\end{array}$ \\
\hline $\begin{array}{l}48 \\
49 \\
50\end{array}$ & Solange & $\begin{array}{l}\text { Tudo bem, mas aí:: nesse caso, olha bem a diferença que dá de uma } \\
\text { disciplina para a outra. Nesse caso, o teu conteúdo É essa:: } \\
\text { competência. }\end{array}$ \\
\hline 51 & Alessandra & {$[\hat{E}]$} \\
\hline 52 & Helena & {$[\dot{\mathrm{E}}, \operatorname{sim}]=$} \\
\hline $\begin{array}{l}53 \\
54\end{array}$ & Solange & $\begin{array}{l}=\mathrm{O} \text { ano passado, quando eu estava com a turma:: de proje::to, eu } \\
\text { fazia isso com matemática, lembra? }\end{array}$ \\
\hline 55 & Helena & $=$ Exatamente \\
\hline 56 & Solange & $\begin{array}{l}\text { Eu tinha um trabalho diferente, eu tinha uma pasta [dessa } \uparrow] \\
((\text { movimento com as mãos) })\end{array}$ \\
\hline 58 & Helena & {$[\hat{E}]$} \\
\hline $\begin{array}{l}59 \\
60\end{array}$ & Solange & $\begin{array}{l}\text { De::sse tamanho:: com os trabalhos de vários níveis. O cara } \\
\text { terminava uma::, eu pega::va outra= }\end{array}$ \\
\hline 61 & Helena & É, é $\downarrow$ \\
\hline 62 & Solange & $=$ Ia fazendo dessa maneira. Tranquilex $=$ \\
\hline 63 & Helena & {$[\mathrm{E}, \mathrm{e}] \downarrow$} \\
\hline 64 & Solange & $=$ Agora quando, você tem- $=$ \\
\hline 65 & Helena & $=$ um outro conteúdo que a leitura $\underline{\text { é instrumento }}=$ \\
\hline $\begin{array}{l}66 \\
67 \\
68 \\
69 \\
70\end{array}$ & Solange & 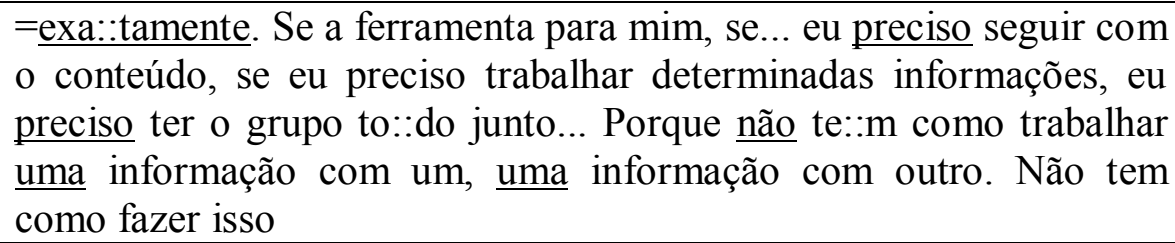 \\
\hline 71 & Helena & É verdade \\
\hline 72 & Alessandra & =Aí você segue, né? \\
\hline $\begin{array}{l}73 \\
74 \\
75 \\
76\end{array}$ & Solange & $\begin{array}{l}=\text { Aí a gente va::i seguindo adiante. Aí a gente vai ter sempre um } \\
\text { pró::ximo texto para trabalha::r, um próximo texto para refazer } \\
\text { aquilo e::e:: ir aparando as arestas. } \downarrow \text { Mas é o que é::.. é o que é } \\
\text { possível- pelo menos é o que eu até agora já consegui fazer. } \downarrow\end{array}$ \\
\hline 77 & Helena & $\operatorname{Sim} \downarrow$ \\
\hline
\end{tabular}

Helena começou a sua pequena narrativa trazendo um resumo ("Eu tinha folhinhas. O conteúdo eu trabalhava em nível- começava do nível básico e ia... até o objetivo máximo que eu queria 
alcançar."- linhas 37-38) antes da ação complicadora, ou seja, da estória propriamente dita. Como ouvinte, Alessandra fez uso do continuador (“Aham" - linha 39) para demonstrar interesse no que foi dito e concedendo assim, um turno maior para a narradora. A professora começou, então, apresentar a narrativa em sequência temporal e lógica, ou seja, ela construiu uma ação complicadora ordenada ("Então, eu ia trabalhando com folhi::nhas. Dava a primei::ra folha, o básico. Aí, eles conseguiam fazer. E alguns não conseguiam. E eu tinha uma folha pronta e dava para o outro que já estava na frente e eu ficava. Então, as vezes, eu fazia folhas a mais porque ele não saía daquele objetivo." - linhas 40-44). Na sua narrativa, uma ação foi gerando a outra: ela dava a primeira folha; eles conseguiam fazer, outros não conseguiam; ela tinha folha pronta e dava para o outro; às vezes fazia mais folhas porque o aluno não saía do objetivo.

Antes de finalizar a estória, a professora fez uma pergunta direta para as ouvintes ("Você entendeu?" - linha 44) questionando a compreensão do que foi dito, não necessariamente exigindo uma resposta, mas uma forma de pedir concordância com o que foi dito e de continuidade do turno. No final, Helena fez o fechamento da narrativa utilizando a coda avaliativa, voltando ao início da estória e reorganizando-a para deixar clara a narrativa ("Então, o meu planejamento, eu planejava por bimestre/ meu mês, > sei lá< ... e era o quê.... ficar produzindo folhas que desse conta:: daquela/ daquele está::gio que eles esta::vam.”- linhas 44-47). Ela, assim, reafirmou que o seu principal trabalho era produzir as folhas de acordo com os níveis dos alunos, isso reforça a construção do seu papel de profissional dedicada que sabia o seu dever a ser cumprido.

Após o turno de Helena, Solange tomou o turno e começou a apresentar as distinções existentes entre o uso da compreensão textual em diferentes matérias ("Tudo bem, mas aí:: nesse caso, olha bem a diferença que dá de uma disciplina para a outra. Nesse caso, o teu conteúdo É essa:: competência." - linhas 48-50), e como essa competência é abordada em cada caso. Após sua fala, todas as participantes concordaram com o que foi apresentado e o turno da fala volta para Solange. Ela fez, então, uso de uma micronarrativa para exemplificar essa distinção e questionou a professora Helena se a mesma se recordava do fato. Após introduzir a orientação do período em que ocorreu a estória e trazer um resumo, Solange estabeleceu interação com Helena e a utilizou para confirmar a veracidade da sua estória, assim, reforçou o seu papel de professora experiente em sala de aula em relação a trabalhar com compreensão textual em diferentes disciplinas (" $=\mathrm{O}$ ano passado, quando eu estava com a turma:: de proje::to, eu fazia isso com matemática, lembra?"linhas 53-54). 
Posteriormente, a professora trouxe para sua narrativa a ação complicadora, organizando a sua estória temporalmente e cronologicamente, com uma sucessão de ações. Solange utilizou, neste momento, além do recurso verbal, o visual, expressando com as mãos a quantidade de material utilizado e produzido ("Eu tinha uma pasta [dessa $\uparrow$ ] ((movimento com as mãos))" - linhas 56-57), dando mais intensidade a narrativa e ao seu trabalho. Dessa forma, ela se posicionou como uma professora aplicada que busca produzir materiais para os alunos, fornecendo-os sempre que necessário, de acordo com o desempenho dos mesmos.

A narrativa da professora mostra a sua experiência em outras disciplinas, tendo em vista que a estória relatada é de um caso relacionado à matemática. Comparando as duas narrativas, é possível perceber que os métodos utilizados pelas professoras são semelhantes. Elas elaboravam atividades de diversos níveis e distribuíam para os alunos de acordo com o desempenho de cada um. Isto mostra que ambas reconhecem e se importam com a questão da leitura e a consideram importantes para ensinar outros conteúdos.

Ao final, as participantes começaram a discutir sobre o uso da competência leitora em diferentes contextos. Solange e Helena co-construíram um discurso sobre o assunto e concordaram que, dependendo da matéria, esta competência não é trabalhada particularmente, o conteúdo da disciplina se torna a prioridade. As docentes construíram o discurso mostrando seus compartilhamentos de pontos de vistas através de interrupção de falas para complementação de pensamentos ("=Agora quando, você tem-=" - linha 64), falas colocadas ("=um outro conteúdo que a leitura é instrumento=" -linha 65), e uso de palavras afirmativas concordando e dando consentimento ao que foi dito ("=exa::tamente. Se a ferramenta para mim, se..." - linha 66 "É verdade"- linha 71; “Simよ”- linha 77).

Para a finalização da narrativa e da discussão do tema, a entrevistadora fez uso de uma coda em forma de pergunta. Ela retomou o que foi narrado e finalizou em forma de questionamento ("=Aí você segue, né?"- linha 72), dando a oportunidade de Solange dar a sua coda. Nesse momento, a professora concluiu com a coda avaliativa em forma de uma micronarrativa hipotética ressaltando a possibilidade de sempre estar trabalhando a competência leitora com os alunos. Para dar início, ela fez um breve resumo e iniciou a sua microestória hipotética, não canônica segundo Labov, com uma ação complicadora ordenada em fatos sequenciais (“=Aí a gente va::i seguindo adiante. Aí a gente vai ter sempre um pró::ximo texto para trabalha::r, um próximo texto para refazer aquilo e::e:: ir aparando as arestas. $\downarrow$ Mas é o que é::.. é o que é possível- pelo menos é o que eu até agora já consegui fazer. $\downarrow "$ - linhas 73-76). 
A narradora revelou, assim, que busca sempre uma oportunidade de trabalhar a competência leitora, utilizando textos com os conteúdos propostos pelo currículo escolar. Mas apesar de suas tentativas e metodologias, a professora assumiu a sua impotência e limite afirmando que isto é o que ela consegue fazer, por enquanto, nesses casos.

No fragmento a seguir, Helena questionou a origem do analfabetismo funcional. As participantes começaram a construir entendimento considerando a falta de estímulo à leitura e ao conhecimento de mundo como alguns dos seus possíveis causadores. Para reforçar o pensamento em construção, Helena narrou um fato extraordinário ocorrido, que exemplifica o que estava sendo discutido. Ela trouxe a estória de apresentação de uma revista para as crianças e como elas reagiram diante desta "novidade". Os alunos não tinham conhecimento, segundo o seu relato, sobre o gênero propaganda e a categoria de assinante. Diante dos questionamentos dos alunos, a professora se mostrou espantada considerando que algo havido sido roubado das crianças.

Para Helena, além da mera dificuldade de compreensão textual que os alunos podem ter por uma defasagem escolar, a falta de apresentação de conteúdos e incentivos da leitura seriam fatores colaboradores para o analfabetismo funcional. $\mathrm{Na}$ teoria, os alunos são considerados alfabetizados, pois apresentam as competências de escrita e leitura, entretanto a compreensão é defectiva. Assim, os alunos não conseguem depreender o sentido dos textos. Além disso, para Helena e Solange, o analfabetismo funcional passaria, ainda, pela compreensão de mundo. Assim, a problemática da leitura se expandiria dos textos para o mundo. A ausência de uma competência leitora interferiria na vida cotidiana dos indivíduos, comprometendo as atividades rotineiras que exigem tais habilidades. Entretanto, isto não caracterizaria como um impedimento da vida social do ser; apenas, as realizações que exigem tais conhecimentos seriam deixadas de lado e poderiam não despertar interesse.

\begin{tabular}{|l|l|l|}
\hline 78 & Helena & Quando eu:: peguei a revista Ciência hoje das Crianças para \\
79 & & trabalhar com a turma 1600 e:: ... eu pedi para eles::/ pedi \\
80 & & informações básicas assim de:: >“ vamos ao índice, o que tem na \\
81 & & revista?”< e eles não sabi::am. Aí eu ..." gente, o que é:: \\
82 & & propaganda? O que é:: ser assinantes? O que é:: ...?”. "Vocês não \\
83 & & sabem?”. Então aquilo ali:: me deixou/ eu.. fiquei de um jeito que \\
84 & & eu falei “ gente como é que pode ? O que foi roubado dessas- ?’. É \\
85 & & muita coisa que a criança não teve contato \\
\hline 86 & Solange & =Uhum \\
\hline 87 & Helena & ... sabe? É muito, é:: está [completamente] $=$ \\
\hline
\end{tabular}




\begin{tabular}{|c|c|c|}
\hline 88 & Solange & $=[$ Defasado $]$ da vida $=$ \\
\hline $\begin{array}{l}89 \\
90\end{array}$ & Helena & $\begin{array}{l}=\text { É::, sabe? Então assi::m, me deu um desespero:: e ao mesmo } \\
\text { tempo a felicidade deles, né. Hoje foi mu::ito interessante [que]= }\end{array}$ \\
\hline 91 & Alessandra & $>[$ Onde está] a informação? $<$ hh \\
\hline 92 & Helena & $\begin{array}{l}\text { ="Tia, eu não achei... eu não achei o::/ eu não tenho nenhu::m texto } \\
\text { pequeno para ler", aí o outro > "procura no [índice]" }<\uparrow\end{array}$ \\
\hline 94 & Alessandra & {$[\mathrm{hh}]$} \\
\hline 95 & Helena & [hh] \\
\hline 96 & Solange & [hh] Muito bom, né? \\
\hline $\begin{array}{l}97 \\
98 \\
99 \\
100 \\
101 \\
102 \\
103 \\
104 \\
105\end{array}$ & Helena & $\begin{array}{l}>\text { "Procura no índice" }<\text {, então... essa nomenclatura assinante }>\text { "o } \\
\text { que é assinante? Assinante, professora? O que é assinante?" }<\text { e aí a } \\
\text { gente dando essa informação, quer dizer::, porque a escola, esse é o } \\
\text { meu questionamento, sempre foi, né ((outra pessoa entra na sala e } \\
\text { fala com a entrevistada)) por que:: a escola, ela... se afasta tanto da } \\
\text { vida? Eu sempre tive essa:: essa tese de que o professor, a escola de } \\
\text { uma forma geral ela tem uma preocupação com conteúdo tão } \\
\text { grande que ela esquece da vida. E por isso... é o que tem de } \\
\text { prazeroso em tudo não vem para a escola. }\end{array}$ \\
\hline
\end{tabular}

Helena iniciou a narrativa trazendo a sequência temporal com as ações cronologicamente organizadas e fez uso do diálogo construído utilizando a fala reportada como ação. Ao reproduzir os questionamentos feitos aos alunos, para os quais ela não obteve respostas, a professora tende a mostrar a ausência de informações dos alunos. Ao narrar a estória, ela se mostrou preocupada com o desconhecimento destes e trouxe isso para o seu discurso ("Quando eu:: peguei a revista Ciência hoje das Crianças para trabalhar com a turma $1600 \mathrm{e}::$... eu pedi para eles::/ pedi informações básicas assim de:: >" vamos ao índice, o que tem na revista?”< e eles não sabi::am. Aí eu ...“ gente, o que é:: propaganda? O que é:: ser assinantes? O que é:: ...?". "Vocês não sabem?". Então aquilo ali:: me deixou/ eu.. fiquei de um jeito que eu falei “ gente como é que pode ? O que foi roubado dessas- ?". É muita coisa que a criança não teve contato." - linhas 78-85).

As professoras Solange e Helena construíram uma avaliação da narrativa considerando os "alunos defasados da vida", entretanto, esta classificação de hiato está relacionada às suas percepções, suas compreensões e suas vivências de vida (" $=$ [Defasado] da vida=" - linha 88). Posteriormente, Helena retomou o turno e se mostrou aflita com a ausência de informação dos alunos. Em contrapartida, se disse feliz por ter conseguido passar algum conhecimento do que ela considerou que faltava para os alunos ("“=́::, sabe? Então assi::m, me deu um desespero:: e ao mesmo tempo a felicidade deles, né. Hoje foi mu::ito interessante [que]=" - linhas $89-90$ ), e por eles terem colocado isto em prática em sala de aula. Antes de a docente narrar a história, a entrevistadora, que estava presente na sala quando o fato ocorreu, se antecipou reproduzindo a pergunta feita em aula (">>[Onde está] 
a informação?< hh" - linha 91). Helena apresentou, então, o fato específico e reproduziu o diálogo para construir a ação complicadora, ou seja, a estória propriamente ("="Tia, eu não achei... eu não achei o::/ eu não tenho nenhu::m texto pequeno para ler", aí o outro > "procura no [índice]"<个" - linhas $92-93)$.

Após a narrativa, todas as participantes riram da estória considerando interessante o fato de os alunos, rapidamente, assimilarem o que foi passado e colocarem em prática. Solange fez um comentário avaliativo da narrativa considerando a estória interessante (“[hh] Muito bom, né?" - linha 96). Helena retomou o turno e concluiu a estória repetindo o final ("> "Procura no índice" $<$,"- linha 97), em seguida fez uso do diálogo construído para suscitar uma nova narrativa, não canônica nos moldes Labovianos, que teria precedido à anteriormente narrada, apresentando os questionamentos inicialmente elaborados em sala ("então... essa nomenclatura assinante >"o que é assinante? Assinante, professora? O que é assinante?"<." - linhas 97 -98).

Para finalizar, ela fez uma coda avaliativa sobre o papel da escola na construção da percepção de mundo e questionou o afastamento da mesma da vida do aluno, se preocupando mais com o conteúdo. Ela afirmou que sempre teve essa "tese", o que a posiciona como uma profissional reflexiva e crítica da vida escolar ("porque a escola, esse é o meu questionamento, sempre foi, né ((outra pessoa entra na sala e fala com a entrevistada)) por que:: a escola, ela... se afasta tanto da vida? Eu sempre tive essa:: essa tese de que o professor, a escola de uma forma geral ela tem uma preocupação com conteúdo tão grande que ela esquece da vida. E por isso... é o que tem de prazeroso em tudo não vem para a escola." - linhas 99-105).

\section{CONSIDERAÇÕES FINAIS}

A pesquisa qualitativa apresentada focalizou a entrevista como um evento discursivo relevante para o entendimento da realidade social e meio de organização experimental dos narradores. As suas participantes agiram em cooperação construindo entendimentos sobre o tema do analfabetismo funcional através da discussão do tema e compartilhamento da experiência profissional. A entrevistadora se apresentou como participante ativa, assim como as entrevistadas se posicionaram como interessadas em apresentar suas percepções e vivências em sala de aula.

A entrevista realizada neste estudo teve como objetivo levantar histórias de experiências com o analfabetismo funcional e a partir disto, analisar a compreensão e a definição de analfabeto funcional das profissionais, observando a construção dos seus discursos e a organização das experiências e posicionamentos apresentados. A 
participação da entrevistadora serviu para orientar as participantes sobre o percurso da discussão e a importância de relatarem as suas experiências. A entrevista se deu de forma aberta e com moldes maleáveis, o que possibilitou a construção de confiança entre as participantes, e estimulou a produção das estórias e compartilhamentos das vivências em âmbito escolar.

A atividade fortaleceu a tese de que as entrevistas são locais de construção de narrativas e apresentam valor significativo que podem colaborar para o entendimento do tema proposto. As histórias narradas foram apresentadas, em sua maioria, para corroborarem com pontos de vistas defendidos. As docentes expressaram suas percepções sobre o que é analfabetismo funcional e construíram narrativas para sustentar seus entendimentos. Trouxeram referências a casos extraordinários que lhes chamaram a atenção, e em alguns casos, apesar de se tratar de fatos específicos, eles são apresentados como habituais no passado. As narrativas não seguiram precisamente as estruturas Labovianas, mas foram consideras como narrativas com ações complicadoras e perfeitamente construídas por suas narradoras, em alguns casos, tendo construções de narrativas complexas com encaixe de outras estórias e micronarrativas, que apresentavam apenas uma sequência mínima de ações.

A análise da estória narrada por Helena permitiu compreender como a docente se posiciona em relação ao analfabetismo funcional em sala de aula. Ela relata que ao se deparar com os casos, ela busca estudar e auxiliar os alunos a superar aquela dificuldade. Durante toda a entrevista ela se posicionou com uma professora preocupada e reflexiva sobre o tema tratado. Ela procurou, também, informar o público sobre o contexto de dificuldade dos alunos e apresentar os métodos utilizados em sala. Helena se mostrou disposta a ajudar os alunos e feliz quando percebeu o avanço dos mesmos. Ela construiu o seu discurso sobre analfabetismo funcional baseado na capacidade de o indivíduo ler, compreender e entender o mundo que o circula.

A docente mostrou um conhecimento sobre os níveis de alfabetismo e a necessidade e a importância de se trabalhar com eles e promover um avanço interpretativo gradual de acordo com a evolução do aluno. Apesar de apresentar esse conhecimento, não ficou claro nas suas narrativas como ela classificaria cada nível e quais competências seriam avaliadas. Ela reforçou a questão da intepretação, mas não abordou a habilidade de escrita, cálculos ou demais critérios que podem ser auxiliadores para a classificação do aluno em algum nível de alfabetismo. 
Solange se posicionou como uma profissional experiente em casos de analfabetismo funcional e em áreas diferentes daquela de sua formação, ciências. Ela utilizou suas narrativas para corroborarem com os seus pontos de vista e, assim como Helena, apresentou o seu método de trabalho, por nivelamentos, entretanto em ambos os casos, não é citado o conteúdo da metodologia. Como Helena, Solange compartilha do entendimento de analfabetismo funcional como uma inadequação na leitura, compreensão e construção de entendimento de mundo. Elas, nas duas últimas interações apresentadas, co-construíram codas avaliativas criando significado e compartilhando entendimento. Ao fazerem uso de parafraseamentos, fala colada e palavras afirmativas, elas demonstram estar em acordo sobre o posicionamento assumido.

Solange também trabalhou a ideia de alfabetismo por níveis. Haveria níveis de entendimentos e os profissionais da educação deveriam trabalhar nesses graus a fim de se alcançar o mais pleno. A docente mostrou um conhecimento da definição moderna de analfabetismo, a qual engloba a competência dos cálculos. Ela lembrou que quando lecionava matemática trabalhava com essa metodologia de níveis, ressaltando a importância da competência leitora em todas as disciplinas. Lembrou, ainda, os empecilhos de se lidar com essa dificuldade nas demais áreas, pois quando o conteúdo da matéria é outro, apesar da leitura ser necessária, esta acaba ficando em segundo plano.

A entrevistadora participou ativamente da interação, apresentando poucas interferências na entrevista, mas se posicionando como ouvinte atenciosa através de ratificadores e risadas. Os risos presentes em diversos momentos da entrevista denotam o clima de descontração em que a entrevista foi realizada, o que auxiliou na criação de um clima propício para suscitações de narrativas. Alessandra não seguiu uma ordenação fixa dos tópicos abordados e não foi necessário solicitar explicitamente que as entrevistadas contassem estórias. Ela se posicionou de forma interessada em compreender e conhecer as experiências e as visões das professoras e, dessa forma foi estabelecida uma relação tranquila e sem pressão de julgamentos de valores sobre o que seria abordado.

\section{REFERÊNCIAS}

BASTOS, L.C. Contanto estórias em contextos espontâneos e institucionais- uma introdução ao estudo das narrativas. Calendoscópio, 3 (2): 74-87, 2005. 
CAMPOS, Sonia Isabel Fabris. A entrevista de pesquisa: um empreendimento coletivo. In BASTOS, Liliana Cabral; SANTOS, William Soares dos (orgs.). A entrevista na pesquisa qualitativa. Perspectivas em análise da narrativa e da interação. Rio de Janeiro, Quartet Editora, FAPERJ, 2013.

MONTENEGRO, Instituto Paulo. Analfabetismo funcional. Disponível em: http://www.ipm.org.br/ipmb_página.php?mpg=4.09.00.00.00\&id_duv=22\&ver=por. Acessado em: 28 de março de 2014.

\section{A AUTORA}

Alessandra Brito de Paiva é graduanda em Letras- licenciatura em Língua Portuguesa e Respectivas Literaturas pela Pontifícia Universidade Católica do Rio de Janeiro. Atualmente é bolsista da capes no Projeto Institucional de Bolsa de Iniciação à Docência- PIBID.

Email: alessandra-brito@hotmail.com 